\title{
GLOSARIO MISKITU, \\ CON COMENTARIO ETNOGRÁFICO
}

\author{
G.R. Heat \\ Bethlehem, Pennsylvania \\ "Traducción revisada y anotada por Danilo Salamanca"
}

INTRODUCCIÓN

(Por Glen Turner de la Universidad de Indiana)

\section{Bases de selección del manuscrito Heath}

Del léxico miskito del reverendo G. R. Heath, completado en 1947 en 510 páginas manuscritas, hemos extraído términos de flora y fauna, incluyendo muchos términos medicinales, especialmente de las plantas utilizadas para curar; artículos del folclore miskito y su organización social, y algunos otros términos. Algunas entradas son pequeños ensayos, como la de $p a$. $s a^{1}$ que distingue entre direcciones cardinales orientadas por cuerpos celestes y direcciones cardinales orientadas de otra manera; también, bajo ka.ti se da el sistema calendario miskito; compare también las entradas pyu.ta saika y miskitu. Otras entradas son más breves, pero en todos los casos, seleccionadas porque incluyen comentarios etnográficos. Las restantes tradas incluidas en el Manuscrito de Heath² (pero no en este artículo) consisten principalmente en un glosario miskito - inglés, sin comentario etnográfico.

\section{Sonidos miskitos}

Las consonantes son: $\mathrm{p}, \mathrm{t}, \mathrm{k}, \mathrm{b}, \mathrm{d}, \mathrm{g}, \mathrm{m}, \mathrm{n}, \mathrm{y}, \mathrm{l}, \mathrm{r}$, $\mathrm{w}, \mathrm{h}, \mathrm{y}$; las vocales son $\mathrm{i}, \mathrm{e}, \mathrm{a}, \mathrm{o}, \mathrm{u}$, más la longitud en todas las vocales escritas con un punto acentuado diacrítico ${ }^{3}$. La i corta y la u corta siempre se combinan con una $a$ corta anterior para formar los diptongos cortos ai y au respectivamente. Diptongos largos ocurren en miskito pero no se encuentran en estos extractos. El signo y se ha utilizado de forma consistente en lugar del ng del autor. Se ha utilizado la minúscula para todas las entradas y la mayoría de los significados. El signo alternante $(\sim)$ se ha utilizado para mostrar más de una palabra o expresión con un solo significado siguiente. Todas las entradas están en orden alfabético; Sin embargo, las vocales largas se tratan como una sola vocal de Dos moras.

$1 \quad$ El acento prosódico, que en miskito viene siempre en la primera vocal de la palabra, usualmente conduce a un alargamiento cuando la sílaba es abierta (es decir cuando la vocal no es seguida de otro segmento en su sílaba) que puede ser de carácter fonológico -cuando hay otra palabra idéntica pero con vocal corta- aquí el acento, y alargamiento de la vocal, aparece marcado con un punto después de la vocal acentuada.

2 El también misionero moravo W.G. Marx hizo publicar en 1961, presumiblemente a partir del trabajo lexicográfico manuscrito de Heath aquí mencionado, un diccionario miskito-español, español-miskito en la imprenta Calderón de Tegucigalpa Honduras: Heath, G.R. y Marx, W.G. (1961). Diccionario Miskito-Español, Español-Miskito. Imprenta Calderon, Tegucigalpa. Este diccionario ha sido reproducido sin mayores cambios numerosas veces, en particular: (1983) Tercera reimpresión. Editorial Hunter Publishing Co. Winston-Salem. EE.UU. Notese, ver nota 3 adelante, que este artículo fue publicado anteriormente.

3 En realidad el miskito fonológicamente tiene solo tres vocales: i,a,u -estas pueden ser largas o cortas, y también ensordecidas, cuando están acentuadas, es decir en la primera sílaba. En esa misma posición, algunos dialectos pueden presentar variantes nasalizadas. Las otras vocales - en particular: /e/ y /o/- aparecen solo en palabras extranjeras o en transcripciones 'foneticas' -es decir transcritas como suenan al oído del transcriptor- de palabras miskitas hechas desde la perspectiva de hablantes de otras lenguas (inglés o español, por ejemplo) que si tienen presencia fonológica de esas vocales. 


\section{Definiciones en español}

La definición o equivalente en español se da en cursiva inmediatamente después de la entrada del miskito; El comentario etnográfico se imprime en romano.

\section{Género y especies}

El género y las especies de los términos de flora y fauna se imprimen en cursiva después de la definición española cuando éstas aparecen el léxico del Manuscrito.

\section{Definiciones no españolas}

Las definiciones no españolas se dan entre paréntesis, y la definición aparece en cursiva con las siguientes abreviaturas en romano: Sp. para el español, Cr. para Creole, Ca. para Carib, Hon. para Honduras, Wayks o wyk. para Wangks y Lad. para los ladinos.

\section{Comentarios etnográficos}

El comentario etnográfico está en romano. Si no se incluye ni el género- especie del nombre ni la definición no española, el comentario seguirá la definición cursiva en español. Algunas definiciones alternas en el manuscrito se han omitido cuando haberlas incluido habría implicado dar explicaciones adicionales, como referencias cruzadas a palabras fuera del alcance de este artículo. Sin embargo, las entradas de referencias cruzadas se han incluido en la medida de lo posible. Para todas las partes musicales se utiliza la escala do ítalo-española fija. Algunos de estos comentarios han sido ampliados a partir de la información dada por Heath en su introducción. La consideración del estilo ha requerido un cierto rearreglo del orden. Todos los cambios fueron hechos para cumplir con el estilo de la revista en que este artículo fue publicado originalmente en inglés ${ }^{4}$. Por ende se ha utilizado un mínimo de puntuación.

\section{Agradecimientos por parte de Heat}

Los nombres ocasionales entre paréntesis al final de una entrada se refieren a personas a las que Heath da crédito por el significado que, no obstante, ha comprobado independientemente en todos los casos. $\mathrm{La}$ abreviatura $\mathrm{Z}$ es para Ziock ${ }^{5}$, el resto de los nombres están escritos en su totalidad. Unos cuantos paréntesis finales dan nombres abreviados de lugares donde se originan ciertos localismos.

\section{EXTRACTOS DEL LÉXICO DE HEATH}

aibakaia kwa la. Ropa antigua de mujeres indigenas, taparrabos, consistente en un trozo de tela de corteza o tela de algodón en forma de una toalla envuelta alrededor de la cintura, plegada y ajustada en las caderas.

aikabaia takaskaia saika. Anti-vomitivo. Una solución de sal normal, 80 gramos -una cucharadita de medida- en una pinta americana de 16 onzas líquidas, es un anti-vomitivo muy eficiente. Dar una cucharadita de la solución cada cinco minutos o cuando la náusea se presente.

aimapaya. La estrella doble Theta Tauri. Dos puntos de luz al oeste de Aldebarán; se dice en la mi- tología miskita que es la pareja humana, un hombre y su hermana, que escaparon del diluvio universal. Aldebarán es el fuego de su hogar. Estas estrellas no son Cástor y Pólux, pero al ser las únicas estrellas gemelas conocidas por la astronomía miskita fueron puestas en las primeras traducciones de Hechos 28:11, en lugar de los Dioscuros.

akak (1) Avispa amarilla; (2) Una especie de lagarto feo y venenoso con ventosas bajo sus pies y una aguijón en su cola que se rompe fácilmente. Graznido aak, aak.

a’ksma. Un tipo de infección del pie, que según se dice se adquiere en lugares fangosos. Se presenta en

4 La referencia de la publicación original de este artículo en inglés es la siguiente: Heath,G. R. (1950). MISKITO GLOSSARY, WITH ETHNOGRAPHIC COMMENTARY. International Journal of American Linguistics. Volume 16.

5 El también misionero moravo Heinrich Ziock, publicó en 1894 un diccionario: Ziock, Heinrich (1894). Dictionnary of English and Miskito Language. Herrnhut. 


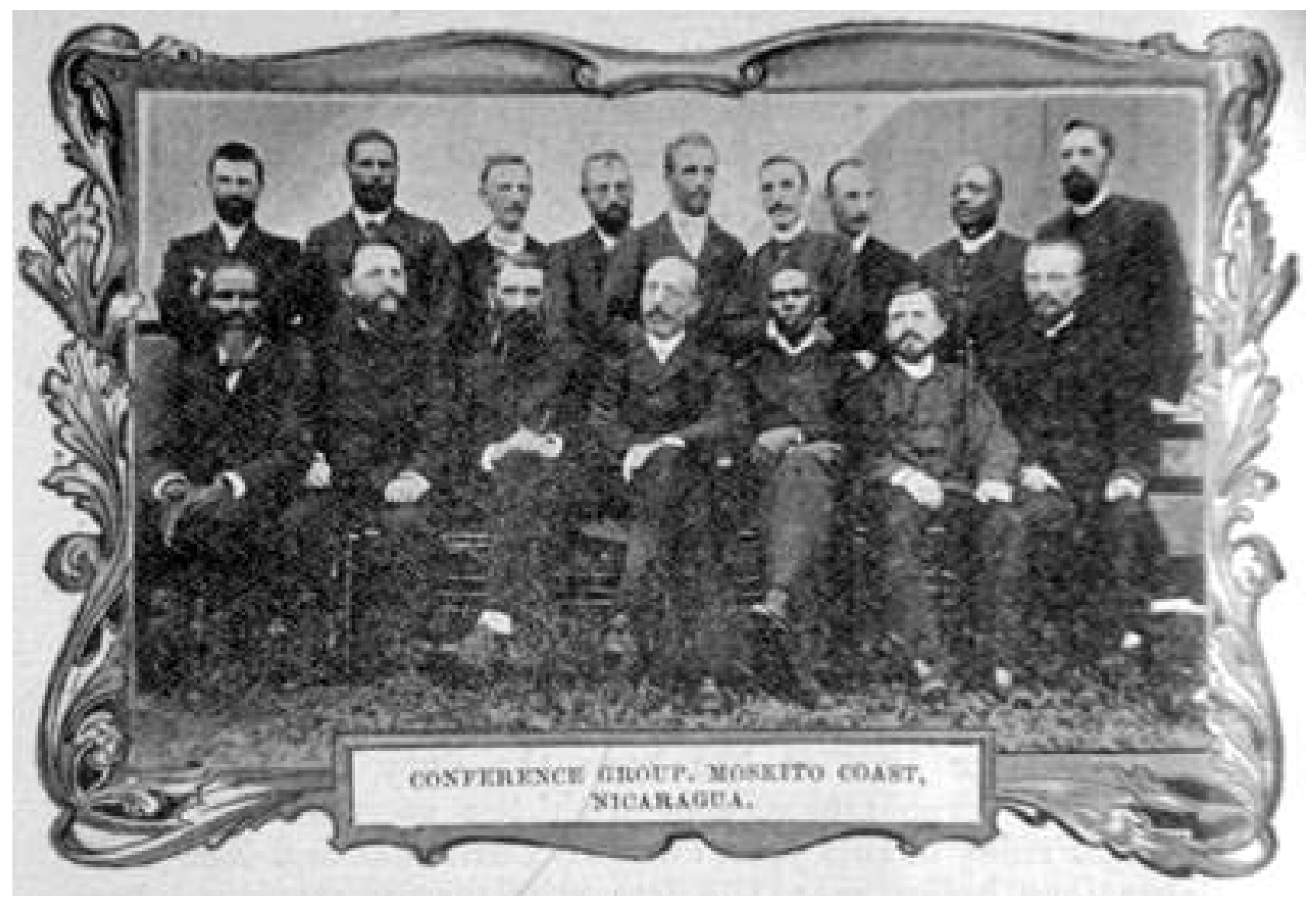

pequeñas ampollas que se unen y se propagan causando hinchazón Se cura lavando el pie en cocimiento de hojas de sauru (sauhru $)^{6}$ u hojas de granadilla o aplicando las hojas trituradas.

a $\cdot$ ksuk. Especie de mamífero nocturno (cuatro ojos), con suave pelaje rojizo y garras curvadas, cuerpo de unas nueve pulgadas de largo; se dice que come gallinas.

alipi na. Jacinto de agua, también conocido como klukum pata, palpa pata, y en el río Wayki conocido comúnmente como kolman tangni porque lleva el nombre del cornishman Charles Coleman, de quien se dice incorrectamente lo introdujo en ese río. Es buena comida para el ganado. y crudo o cocido puede ser utilizado por los seres humanos.

6 sauru o sauhru: especie de bejuco medicinal con hojas moradas que crece en la playa. N.c. Ipomea pes-caprae (de acuerdo a Cyril Hardy Nelson Sutherland (2008). Catalogo de las plantas vasculares de Honduras pg. 321. Llamado en español 'bejuco de carey' o 'bejuco de cintura'. En inglés 'bayvine'. almuk a -wra. Una persona legendaria del que se habla muy raramente y quien vino del otro lado del mar. Aparentemente corresponde a Balam Votán de Yucatán.

alwoni. El espíritu del trueno, considerado por algunos como la divinidad principal.

antaman · (1) Especie de avispa azulada que vive en la tierra; aguijonea bastante fuerte, pero solo si se le pisa. Ataca y come arañas. (2) Hunter man, término prestado del inglés, utilizado en Honduras para referirse a un hombre que busca árboles de caoba, árboles de caucho o caza para alimento en los campamentos forestales.

asay: Colina cubierta de bosque; en territorio sumu todo el bosque es montañoso, pero la palabra misma parece significar bosque. En miskito, el énfasis parece estar en la elevación sobre el territorio circundante. Así que en Sandy Bay, que es territorio plano, insla asayra daukaia significa: hacer plantación 
en las tierras de los bosques situados en las crestas levemente elevadas cerca de las aldeas. (R.F.Bishop)

asangbushna. Colina quemada. Nombre sumu de una montaña en el río Butuk o Patuca, que según los indígenas es un volcán. Exploradores más recientes insisten en que no tiene cráter y sugieren que los incendios observados pueden deberse a gases naturales.

asido $\cdot$ ra. Muy pequeña garrapata de hierbas, de color escarlata brillante o rojo carmesí. Llamada piojo de hierba en Nicaragua y Honduras, piojo de la patata en Jamaica, bête rouge en algunas islas antillanas. Kerosín o infusión de cuasia (N.c. Cuassia amara) aplicados a las piernas las mantiene alejadas; y una solución de una onza de sal de Epson en un litro de agua alivia la picazón severa de las picaduras.

auas (awas). El pino y su madera; antorcha de pino; Pinus oocarpa (pino, Ocote). Este pino de hoja larga es la única especie que se encuentra en territorio miskito. Es el árbol nacional de Honduras.

auaspi· (awaspi) Especie de árbol, ocotillo. No es una conífera, tiene hojas pequeñas y pequeñas flores blanquecinas. Su madera se quema como el pino, pero es demasiado valiosa para ser quemada ya que se asemeja al ciprés en color, textura y durabilidad. Solamente se encuentra tierra adentro.

aubiya. El gran espíritu del aire; literalmente, el que dibuja los vientos. Se dice que vive en la cumbre de Yaluk o de alguna otra alta montaña; considerado por algunos como el jefe de las divinidades miskitas.

auka. Especie de árbol alto, Tecoma (Sp. Cor$t e z)$, con una madera de savia amarilla pero principalmente muy dura, durable, de color verde-negro; madera lisa que rompe hachas pero fácilmente se puede aserrar. Las brillantes flores de color amarillo dorado en forma de trompeta aparecen en profusión en febrero y mayo. Se dice que la cocción de la corteza puede aliviar las inflamaciones del bazo y del hígado y curar la disentería. Parece que contiene berberina.

auya saika. (1) Una especie de mala hierba amarga (Cr. Madame Complaise) que crece en las playas del río en la estación seca. Su ingesta produce una fuerte purga que, según se dice, después logra sedar todo el cuerpo dando una sensación de bienestar. (2) Igual que kaybaia (Sp. Santa Marta).

awalwas Tawolwas. (1) Nombre de un afluente del Wangki superior; (2) nombre de una montaña cerca del afluente, que los indios dicen es volcánica y un rival de asaybusna al cual arroja piedras. Significado del Sumu awal desconocido ${ }^{7}$.

awan (awang): Especie de árbol grande cuya corteza, suministrada en decocción, es un purgante vomitivo violento. El nombre Aguan dado al río, también conocido como río Romano, es casi con toda seguridad una corrupción española de away. En épocas pasadas, los miskitos reclamaron su desembocadura, a lo largo de la playa, como el límite occidental de su reino, pero nunca vivieron al oeste del río Negro. (N.c. Guarea kunthiana. De acuerdo Cirilo Nelson (2008): Catálogo de las plantas vasculares de Honduras. Editorial Guaymuras. Tegucigalpa).

a yalila. Especie de ave, de excelente trino musical; principalmente de color sepia marrón, las plumas recortadas en puntos con marrón brillante y el pecho marrón claro. Llamada ka $\cdot \mathrm{t} \mathrm{ka} \cdot \mathrm{t}$ y kirr kirr; al macho a veces se le llama kakakak. Su principal melodía es mi-do-mi-do-mi-do-mi-sol-la, trillado y con variaciones.

ba - diltuk. Nombre de un afluente del río Ras, aurifero. Los mineros ignorantes sobre los indígenas corrompieron su nombre a (bottle two) dos botellas. De tal manera que funcionarios del gobierno escribieron así su nombre (dos botellas) en sus documentos. El nombre es considerado por los payas como de origen sumu.

balyanta balyanta ta "wa. Una variedad de patata dulce con pulpa y cáscara color púrpura y en parte color violeta de vid y hojas. Fue traída de la tierra de los indios guaimi (Valiente, Balyanta) en $\mathrm{Pa}-$ namá. Se vuelve azul ultramar en la boca.

7 En mayangna awal: significa achiote (pg. 27: Melba E. McLean Cornelio (1996) Diccionario Panamahka. Managua-CIDCA) Was, como es sabido, y común en las toponimias, significa agua. 
basala. Una especie de maleza, Serjania inebrians, utilizada para matar o atontar a los peces al azotar con ella el agua, en la represa de un arroyo. También se usa en polvo, con guaco, mukula, jengibre y ajo, como ingrediente en un remedio favorito para la mordedura de serpiente. En español se le llama barbasco, aunque este nombre se da a varias plantas y significa estrictamente barbasco o gordolobo. En este sentido, basala no es barbasco. ${ }^{8}$

bisbaia. Hedor, pestilencia, cualquier cosa con olor fétido. Usado para bananos y plátanos machacados y envueltos en hojas de waha ${ }^{9}$, enterrados, dejados para descomponerse y luego comidos como un manjar.

bra . (1) Amigo cercano, significado similar al de 'libra' (ver definición de 'libra' aquí mismo, adelante). (2) Flauta, tubo musical. La flauta miskita era hecha de pequeños pedazos de bambú y tenía cinco notas aproximadamente, de si a fa en la escala española. Aparentemente las diferentes flautas de hombre podían ser reconocidas por una diferencia de tono, como en la historia de Naklili (ver entrada para naklili adelante).

bru's. Nombre de unalaguna grande, en Honduras, y también del pueblo situado en su costa sur. Este nombre es una corrupción de Brewers. La laguna fue conocida anteriormente como Brewer's Lagoon, por el pirata Bloody Brewer que vivió en la montañosa isla Cañón situada en la parte oeste de la laguna.

busuk. Una palabra que imita el sonido de algo que se hunde en el agua. De allí el significado de la palabra siguiente.

busukra. Se llama así a los pantanos acuosos con espeso crecimiento de hierba y malezas; un crecimiento

8 De acuerdo a Cyril Hardy Nelson Sutherland (2008). Catálogo de las plantas vasculares de Honduras. Ed. Guaymuras, Tegucigalpa; el nombre científico de la planta llamada 'basala' en miskito es: Paullinia pinnata pg. 996.

9 waha: la bijagua (N.c. Calathea insignis. De acuerdo a Heath y Marx (61), ver nota no.2. Cyril Hardy Nelson Sutherland (2008), pg. 619-620, identifica la planta llamada waha en miskito con el N.c. Heliconia hirsuta y también Heliconia pogonantha (señala además que esta última es llamada también rihrut en miskito y wakipan en mayangna). de pasto enmarañado bastante firme, pero fácil de atravesar deslizándose sobre el agua que está debajo.

dar. Especie de planta trepadora que, se dice, cruje con el sonido de dar-r-r mientras se balancea de un lado a otro. En la leyenda de los Wiswis se dice que tiene la propiedad de hacer invisible cualquier objeto o persona atada con él.

dwarwa (1). El jumbo y su vid. N.c. abrus precatorius. Mal llamado licorice por los creoles. La confusión de los diccionarios seguramente descansa en un malentendido. Esta semilla está en conexión supersticiosa con los jumbies, espíritus desencarnados o demonios, de las Antillas; (2) en Wayki se dice que es lo mismo que wislu ${ }^{10}$

gua·ko (en la escritura tradicional miskita: waku). Guaco, nombre de diferentes variedades de Aristolochia, especialmente A. guaco o anguicida. También significa un árbol con una corteza amarga usada contra la malaria. Para mordedura de serpiente tomar cerca de cuatro pulgadas de la vid gruesa del guaco, la viruta cortarla finamente y hervirla en medio litro de agua. Dar media copa cada media hora. Es mejor aún combinándola con kuntribu. También se necesita tratamiento local en la mordedura.

i·bo (en miskito tendría que ser ibu) Especie de árbol gigante, con espolones o contrafuertes y madera muy dura, como palo de rosa, y resistente a las hachas; no se encuentra al norte de Awaltara ni al sur del río San Juan. Está cubierto con flores rosadas en febrero y produce una fruta que contiene una pulpa comestible y una semilla muy dura cuya interior también es comestible y buena, pero se utiliza principalmente para hacer un aceite valioso. ${ }^{11}$

10 Cyril Hardy Nelson Sutherland (2008), además de la planta de N.c. abrus precatorius, pg.465. señala que el mismo término es usado en miskito para la planta de Nc. Ormosia coccinea (Ilamada coralillo en español), pg. 501 y para Erythrina costarricencis, pg.488 -Para esta última no proporciona nombre vulgar en español. 11 Posiblemente se refiera a iban (níspero o palo de chicle, según Heath y Marx (61), o iban (wainka), literalmente 'níspero macho' cuyo nombre científico según Nelson Sutherland (2008) pg.1005-referencia completa en notas anteriores- es: Pouteria reticulata (nombre vulgar 'zapotillo' en español). 'Ibo' o 'ibu' no aparecen ni en Heath y Marx (61) ni en Nelson Sutherland (2008), ni en Vaughan (59). 
ihiri. Especie de plantas leñosas, aóides, que crece en agua o pantanos. La fruta es muy grande, cuando madura la pulpa de cada fruta se arruga pero la semilla cuando está cocinada correctamente es parecida a patatas. El espádice de la flor se llama a veces chichi banana.

Itikmuk itimuk. Especie de termita (Cr. duckant) que agujerea la madera y la come desde el interior. También es llamado usra pihni.(literalmente 'comején blanco') Para combatirla se puede pintar la madera con una solución de sulfato de cobre, 1 parte en 256. El suelo alrededor de los postes también debe ser tratado. Esto se dice que da una buena protección.

kakamuk ki wka. Especie de vid, con jugo lechoso y pequeñas hojas carnosas. Cuando se hierve se vuelve duro y se utiliza para atar hojas de paja.

ka'kmapara. Agujero excavado por agua corriente en la base de un pequeño precipicio, considerado según Ziock, como el lugar en que acecha un espíritu malvado, pero más probable, la serpiente ka·kmapara. (2) Una mítica serpiente o gusano cuya mordedura supuestamente causa una hinchazón reumática dolorosa. (3) Hinchamiento que se supone resulta de tal mordedura pero que es a menudo artritis gonorroeal.

kangbaya. ${ }^{12}$ Botón de hierba, Borreria osmoides o laevis (Sp. Santa Marta), una especie de maleza delgada con pequeñas flores blancas, cruciformes, a veces también llamado auya saika. El líquido obtenido por maceración en agua fría se utiliza para lavar la arena de los ojos. También se administra tomado, contra la mordedura de serpiente; las hojas machacadas se aplican también en el sitio de la mordida. Igualmente machacadas sirven para aliviar el dolor

12 Heath y Marx (1961), pg. 34, definen este término -kangbaya- como: la yerba Santa Marta (N.c. Barreria omoides o Barreria laevis), y la palabra derivada -kangbaika- como: (creencia indígena), cualquier remedio contra el hechizo. Dionisio Melgara Brown (2011) en su Diccionario Español- Miskito, Miskito-Español. Mangua, fondo editorial Instituto Nicaraguense de Cultura (pg.289), siguiendo en esto también al diccionario de Adolfo Vaughan Warman (1959), Managua, Talleres Nacionales. Pg.99, define esta palabra 'kangbaya', de la siguiente manera : antídoto, contraveneno; contra-medicina de cualquier maleficio; remedio contra cualquier hechizo (creencia indígena); amuleto preparado mediante una invocatoria, para contrarrestar algún maleficio y para protección de los malos espíritus (el verbo 'kangbaia' significa, entre otras acepciones: expeler, expulsar). de cabeza aplicándolas en dicho sitio. La infusión o decocción, especialmente de la raíz, sirve contra los dolores uterinos.

karswaki. Nombre utilizado para asustar a los niños, se supone que es un demonio o un hombre caníbal.

ka·ti, luna; mes lunar. De allí lo siguiente: holide 'ka'ti' alide 'ka'ti', luna de vacaciones, corresponde al primer mes del nuevo año que comienza en las vacaciones de Navidad que a menudo eran indebidamente prolongadas - por lo tanto corresponde aproximadamente a enero. kuswa ka'ti, luna tortuga, segundo mes, cuando la tortuga pone huevos -febrero-. islu 'ka'ti', luna del lagarto, segundo mes, cuando el gran lagarto verde pone huevos-última parte de febrero y principios de marzo-; este término no es de uso común. kakamuk ka'ti', luna de la iguana, tercer mes, cuando la iguana pone huevos, - marzo. wli/lih wainhka ka 'ti', luna tortuga, cuarto mes de la tortuga macho -abril. wli/lih mairin ka'ti, luna de la tortuga hembra, quinto mes, -mayo; en Honduras se llama lagrit kati. Luna de la tortuga caguama. Tisba ka'ti', luna de la fruta de pan, sexto mes, cuando la fruta de pan está madura -parte de mayo y parte de junio. Li ka'ti, luna de lluvia, séptimo mes, cuando en Nicaragua comienza la temporada de fuertes lluvias -junio; en Honduras, donde la mayor estación de las lluvias comienza en noviembre, esta luna se llama luna de cedro, swa 'ka'ti', porque el fruto del cedro bastardo madura. Pasta'ra ka'ti', luna de viento, octavo mes, cuando en Nicaragua el viento es más feroz -julio. Sikla ka'ti 'sikla, luna del pájaro sikla, noveno mes -agosto; en Honduras, donde no se conoce el sikla, se llama wis. Sirpi' ka'ti', luna del pequeño wis. wi 's ka' ti 'wis moon, décimo mes, cuando llegan los pájaros wis-septiembre. Pra'ri 'ka'ti', luna de huracán, undécimo mes, cuando la mayoría de los huracanes nicaragüenses ocurren en octubre; en la actualidad a la gente no le gusta este nombre y dice más bien: saut ka'ti 'luna de viento del sur oeste, pero en Honduras el viento de ese tiempo es principalmente hacia el sur y su (saut) significa sur-este. Ya'bra ka'ti viento del norte, duodécimo mes, cuando las tormentas de viento en el norte suelen establecerse en noviembre. En Honduras estas tormentas son mucho más severas y ya'bra es noroeste; éste es el comienzo de la estación lluviosa 
de Honduras. Kristmas ka'ti ' $\sim$ krismas ka'ti', luna de Navidad, decimotercer mes, normalmente incluye el festival de Navidad -diciembre.

Estas lunas no forman un calendario estricto y no hay medios de ajustar el año lunar al solar. El intento de hacer que los nombres correspondan a nombres ingleses o españoles es comúnmente mal entendido, pero ha sido seguido en la escritura de cartas por aquéllos que tienen un poco de educación.

katski. La laguna y la barra, o entrada desde el mar de Caratasca. También un pequeño asentamiento al noroeste de la barra. Anteriormente también una aldea en la playa algunas millas al sur-este, ahora abandonado. La boca de la laguna que conduce a la barra es de una milla cuadrada. En el lado sureste hay una isla formada por las dos bocas de un pequeño arroyo. Se dice que éste fue el centro de un malogrado intento de colonización del escocés Gregor Macgregor hacia 1810. Desde entonces, la isla era conocida como la Llave Escocesa cuyo nombre, de acuerdo con reglas fónicas mískitas (scot's ki) se convirtió en katski, alargada a veces como kataski. Otros afirman que kataski es una pronunciación corta [apocopada o reducida] de ka'rata'ski que significa pasto de seda sucio (kara taski), lo cual los españoles cambiaron por Caratasca, pero originalmente los españoles la llamaban la laguna de Cartago.

ke ·p. En inglés cape. Nombre de la ciudad en la laguna de Cabo Gracias, anteriormente la cabecera del distrito del Cabo. La parte meridional de ella es Pullingtown o Pullintaun, el norte es Si tawa $\cdot \mathrm{la} \sim \mathrm{Si} \cdot-$ tawo la. Los indígenas llamaron a toda la aldea ke'p sin saber lo que significaba la palabra. Cuando fue construida una ciudad en el verdadero Cabo en 1901, entonces los indígenas llamaron a este sitio Wangkibar y continuaron dando el nombre de Ke'p al casco antiguo de la aldea; ahora oficialmente en español es Cabo Viejo. Este nombre oficial se reproduce a veces como Ke'p almuk. La geografía de todo el distrito se ha confundido por el cambio de las desembocaduras del Wangks. La isla de San Pío, famosa en la negociación política ha dejado de existir como tal. Wangkibar fue totalmente destruido por el huracán de 1941 y ha sido abandonado.

$\mathrm{ki} \cdot \mathrm{sauri}^{13}$. Especie de cilantro, Eryngium (Sp. Culantro, Cr. Fit-bush). Un té hecho de la planta en- tera y bebido con frecuencia durante muchas semanas controla la epilepsia.

ki· su. ${ }^{14}$ Especie de palma delgada con hojas grandes y espinas largas. Produce racimos de fruta redonda que contiene un poco de jalea blanca y una semilla grande. De la semilla se extrae un aceite valioso que ahora no es común.

Knu. ${ }^{15}$ El lirio de la araña, Pancracio. Generalmente blanco puro, pero en la variedad más grande tiene un toque naranja. Crece salvaje en el agua, pero se trasplanta a tierra firme. Este bulbo es un purgante vomitivo drástico, pero en pequeñas dosis se puede utilizar de la misma manera que la escila o cebolla albarrana.

kauna pa. Montaña en la orilla izquierda del río Butuk o Patuka, a cierta distancia hacia abajo de la desembocadura del Wampu. Según la leyenda sumu habría sido el hogar de Maisahana, nuestro creador y su esposa madre Ituana, los antepasados de todas las tribus miskitas y sumus.

kra·bo. Especie de árbol, Byrsonima crassifolia (Sp. nancé), que proporciona excelente leña; posee una corteza astringente cuya decocción se utiliza para curar la disentería. Produce una especie de cerezas amarillas, como bayas, muy amargas, que se conservan embotelladas en agua fría. Puede ser comida cruda o enriquecida con azúcar. Comida de de engorde favorita de los cerdos.

kubus. Chimenea nativa construida al colocar tierra arenosa en una especie de caja u horno sobre una plataforma de bambú fijada en postes sostenidos por palos bifurcados. Estufa de arcilla hecha a la manera de los caribes en Honduras.

$\mathrm{ku} \cdot \mathrm{ku}$ awrika. Coco a la deriva; término aplicado para ridiculizar a los extranjeros.

\footnotetext{
13 Nelson Sutherland (2008), identifica esta planta miskita -kisauri-con el nombre científico Eryngium foetidum, vulgarmente conocida en español como culantro de pata, culantro de pozo o culantro de tripa.

$14 \quad$ Heath y Marx (1961) definen esta palabra- kisu- de la siguiente manera: el coyolillo, palma delgada con racimos de frutos oleaginosos. N.c. astroncarium sp. ( Añadiendo que también es así llamado un árbol parecido al cacao).

15 Nelson Sutherland (2008) pg. Identifica al pancracio como N.c. Hymenocallis littoralis. Pg.65
} 
kuntribo. Vid amarga, Aristolochia trilolobata; huele como hoja de guanábana; es un remedio muy importante para la mordedura de serpiente, la malaria, la viruela y la disentería. Dosis: tres hojas o la cantidad que se emplea para el gwa ko (waku).

laimus damni (literalmente limón dulce). Bergamota (citrus bergamia). Limón dulce, con pulpa blanquecina no muy sabrosa pero con jugo refrescante. La cáscara, excesivamente fragante, es útil, ya sea picada o rallada, para hacer conservas y para la fabricación de perfumes.

laka. Arbol de algarroba tropical o algarrobo, Hymenaca courbaril (Sp. algarroba, guapinol). Media onza de corteza hervida en una pinta de agua, es usada por los indios para la disentería, y por los ladinos para el bazo hinchado.

lalma. En ángulo recto con la orilla, mar o agua adentro. Por lo tanto, en la costa atlántica nicaragüense indica, mar adentro, hacia el este. En Honduras, dada la orientación del litoral, mar adentro indica dirección noreste o norte. En un río, indica hacia el medio. Para designar el este como punto cardinal uno oye yu' mi'na (literalmente 'pie del día': sol naciente, punto donde nace el sol).

la.pia $\sim$ la.pya. Amigo que en el nacimiento de un niño es llamado para cortar el cordón umbilical. Posteriormente este amigo guarda con el niño parecida relación a la de un padrino con su ahijado; y con los padres del niño como alianza entre amigos.

li la la mia (lamia, forma construida de limi). Tigre de agua. Se dice que es un tigre de patas palmípedas, que viven en el agua y es capaz de atacar y comer un caballo, pero considerado por los extranjeros como leyenda. Hace años se ofreció una recompensa para la piel y los pies del animal, pero nunca fue respondida.

libra. Amigo o amiga por pacto o ceremonia indígena. Siempre del mismo sexo. Ciertas ceremonias inofensivas se observan al hacer la alianza ${ }^{16}$.

16 En Heath y Marx (61), pg. 60, se asimila esta relación a la de compadre o comadre, se añade que al morir uno de los miembros de esa relación de 'libra' el sobreviviente si es varón llama 'libra pani' a los hermanos del difunto y si se trata de mujeres a las hermanas de la difunta. Vaughan Warman (1959) Ilama a esta relación 'hermano-a adoptivo'. Pg. 148. lilka ${ }^{17}$. Semejanza, imagen, sombra, espíri$t u$. No está muy claro cuál es el significado original, porque el espíritu humano se considera un copia del cuerpo en miniatura, de aproximadamente tres pulgadas de largo. Anteriormente, la palabra también se usaba para el Espíritu Santo, pero esto llevó a tanta confusión que se ha abandonado en favor del término espíritu $\sim$ pirit, una palabra preferida por los propios indígenas.

limsi. Abedul rojo de las Antillas, árbol de trementina. Elaphrium simaruba. No es un abedul verdadero. La infusión de sus hojas es excelente para la tos incluso para la tisis. La corteza es usada a menudo para hacer el té que se dice es para purificar la sangre. Algunos autores hondureños recomiendan la corteza de forma oral y en aplicación externa para la mordedura de la serpiente.

liwa. (1) Gusano, larva, oruga, estrella de mar. (2) El espíritu maligno que vive en el agua ${ }^{18}$, considerado a veces como uno solo: liwa, o a veces como muchos: liwa nani; pero el plural puede referirse a los espíritus subordinados que sirven a la gran li.wa . Ziock dice que también significa sirena, pero esto parece ser una identificación criolla de las Antillas. Se decía que Li·wa había vivido en el gran remolino en Namak almuk en el alto Wanks y que había matado en este río a todos, menos a uno, de los integrantes de la tripulación sumu de una canoa. Se decía que otro li · wa vivía en la parte poco profunda de la parte sudoriental de la laguna de Caratasca y que hundía los barcos y ahogaba a los ocupantes. Se decía que los li·wa eran blancos y que tenían un barco en lugares profundos bajo el agua, y que vivían en la cabina de dicha embarcación.

li.wa mukya ${ }^{19}$. Especie de árbol con madera muy suave y flores grandes de amarillo dorado en forma de platillo. En Honduras se llama karskwaya. Utili-

17 lilka alkaia (literalmente 'atrapar imagen': fotografiar, retratar (Heath y Marx (61) y Vaughan Warman (1959).

18 Vaughan Warman (1959) añade: liwa mairin (sirena) y liwa yapti (hechicera que tiene pacto con las sirenas).

19 Nelson Sutherland (2008), pg. 230, Identifica la planta llamada en miskito liwa mukya (literalmente 'placenta de liwa o gusano) o karskwaya con el nombre científico: Cochlospermum vitifolium, y le atribuye los siguientes nombres vulgares en español: chaparro, jicarillo, poroporo y mano de león. 
zado para postes vivos en las cercas. La variedad de las Antillas, con flores dobles y sin fruta, no se encuentra en el territorio miskito.

li·watiskla ${ }^{20}$. Una estrella en el sureste, cuya identificación se ha olvidado ahora, pero, casi con toda seguridad, en la constelación de Escorpio; de ahí el nombre del viento sureste o este-sur-este. En Kruta, li·watiskla es el tiempo cercano a la Navidad cuando muchos animales salvajes, como los ciervos, se supone que caminan más libremente. Escorpio reaparece unos días antes de Navidad, levantándose justo antes del sol; por ello Antares se llama kristmas.

lu pa tangni ${ }^{21}$ (literalmente flor del hijo-a ) (1). Hermosa especie de orquídea utilizada como medicina para causar la fertilidad de las mujeres. (2) Una variedad de orquídeas (Sp. Vaca) muy apreciada, que se encuentra cerca de Bocay y en otras partes del interior. (3) Una planta parecida a una caña con hojas cortas, carnosas, peludas y grandes flores de jengibre que crecen en espirales. El jugo del tallo es amargo; succionado libremente se dice que es un remedio para la gonorrea.

lu·palila. Especie de lagartija muy mansa. Se considera un presagio de la concepción, y para ese efecto la frotan sobre el vestido de la mujer que se quiere que salga embarazada. ${ }^{22}$

mairin albika. Esclavo de una mujer, antes se le decía así en burla al hombre que asiste a su esposa en su trabajo.

mang·gu (mangku). Árbol y fruta de mango. La mayoría de las partes de este árbol son útiles en medicina. La decocción de la corteza de los árboles viejos, especialmente la corteza exterior, además de

20 Heath y Marx (1961) proporcionan la expresión: li watliskla mina krawisa (literalmente sopla del pie de liwatiskla) que significa -sopla del sur-oeste.

$21 \quad$ Heath y Marx (61) dan como equivalente de la orquídea 'lupa tangni' el término también miskito 'wiyakis'. Dado el significado de la expresión -lupa tangni: flor del hijo-a- probablemente lo que estas flores tengan en común es que pueden ser utilizadas como propiciadoras del embarazo.

22 Heath y Marx (61) añaden que cuando aparece espontáneamente en el vestido de una mujer es señal de que está embarazada. ser levemente antiséptica y suavemente astringente, es una febrífuga y anti-malárica que supera, dicen algunos, a la corteza de quina. En una sola dosis de un cuarto de litro sirve para evacuar serosidades. Funciona igualmente contra la disentería; se hierve una onza en 16 onzas líquidas de agua. La infusión de hojas - un puñado en medio litro- sirve para un buen lavado de la boca y también detiene rápidamente el sangrado de los dientes. Se dice que las semillas de la fruta, limpias, trituradas, y hervidas en una cantidad comparable de agua, y luego colados, son excelentes contra la disentería y es un buen antiparasitante. Puede ser recocida para hacer jarabe, con dos partes de azúcar. La exudación resinosa es utilizada por algunos para curar viejas llagas e incluso gonorrea.

matsiksa. La gran serpiente rey negro ${ }^{23}$. Tiene una garganta blanquecina o amarilla, mata y come serpientes venenosas y también ratas; a veces come huevos. La historia de que azota a ciertas personas con su cola carece de pruebas fiables.

miskito $\sim$ miskuto. ${ }^{24}$ El nombre de la principal tribu indígena de lo que ahora es el este de Nicaragua y noreste de Honduras. El territorio ocupado por ellos se extendía desde la desembocadura del río Negro hasta el extremo meridional de la Laguna de Perlas, pero reclamaban su soberanía hasta el extremo oeste de la desembocadura del río Romano o Aguán, Awan o Aun y hasta el sur de Greytown, o San Juan del Norte. No parece haber pruebas de la afirmación de Charles Algernon Hodgson y otros, en el sentido de que algunos de ellos habitaban la región entre Laguna de Perlas y Greytown y que fueron aniquilados por la viruela. Los indígenas dispersos que vivían allí eran probablemente de la etnia rama. Los miskitos estable-

23 Heath y Marx (61) la llaman 'culebra mica' en español.

24 Como aparece señalado en la nota 3, arriba, el idioma miskito no distingue fonológicamente entre /u/ y /o/ y posee una sola vocal pronunciada con la masa de la lengua colocada hacia atrás en la cavidad bucal, usualmente escrita /u/: las palabras nativas del miskito no contienen la vocal /o/. Es por eso paradójico que una palabra emblemática de la lengua y el grupo étnico sea pronunciada, incluso al hablar miskito, como se pronuncia en español. El tema de saber si hay que decir 'miskitu', como debería de ser si fuera una palabra nativa de la lengua, o 'miskito' como se pronuncia más fácilmente en español, es un tema de discusión recurrente. Que los mismos miskitos pronuncien 'miskito' en su lengua sugiere que es una palabra de origen externo al idioma. 
cieron cierto grado de supremacía en varios puntos de la costa costarricense y en la región de Bocas del Toro en Panamá, por medio de expediciones piratas.

El origen del nombre mískito es bastante incierto. El territorio era conocido como Mosquito Shore y la Costa de Mosquitos. Escritores del siglo XIX, tanto alemanes como ingleses, afirman, errada pero vigorosamente, que mosquito es una corrupción de mískito. Pero estos escritores no conocían todo el país. Tierra adentro, a muy corta distancia desde el mar o de cualquier laguna, comienza un cinturón de tierra pantanosa donde los mosquitos son lo suficientemente numerosos y feroces para matar a un hombre desnudo y desamparado en una noche. Además, la palabra mosquito significó originalmente cualquier clase de mosca pequeña $y$, en español hondureño, en la actualidad significa la cruel mosca-botella, que es nuestro mosquito llamado zancudo. Lo que con todas las diversas especies ahora llamadas mosquitos en inglés se agregó a los numerosos flebótomos, las moscas botella, las moscas del doctor o las cazadoras negras o amarillas o rojas, moscones, y otras plagas similares. Por lo cual no es de extrañarse que los primeros exploradores que vinieron a Honduras hayan llamado a toda la región territorio de mosquitos.

Varios escritores españoles usan el término de indios moscos. La gente en la actualidad dice: yang nani miskito: somos miskitos. Pero idiomáticamente se refieren a sí mismos como: upla aingwa: humanos verdaderos. Parece no haber evidencia de que la palabra miskito fuera conocida como un nombre tribal antes de que el nombre Costa Mosquita estuviera en uso. Algunos piensan que el nombre tribal original era waikna. En la actualidad no existe el indígena miskito puro. Algunos dicen que nunca existió un miskito puro sino que los tipos aparentemente más puros eran descendientes de los prinsu y sumos bawihka que adoptaron la lengua miskita. Ha habido twahka de habla miskita o sumos panamaka en el Wangks y también, se afirma, en Auka. Edward Conzemius, en la página 17 de su estudio etnográfico de los indios miskitos y sumus de Honduras y Nicaragua, consideró que los miskitos se originaron en el matrimonio mixto de bawihka sumus con esclavos africanos naufragados.
El término miskuto se escuha solamente en aldeas tawira cerca de la costa del mar donde los habitantes se llaman miskuto aijwa, miskitos verdaderos, aunque obviamente se les nota ser, en parte, descendientes de africanos y dan, a los miskitos del interior el nombre de tawira. Los miskitos wangki llaman tawira a todos los que están cerca de la costa del mar, y ambos grupos llaman a los de Honduras ma.m. En los baldam nani de la montaña, el elemento de la ascendencia africana es reconocido francamente. Todos los miskitos fueron llamados weiya por los sumus, pakda por los ramas, idudu por los caribe, $\mathrm{ku} \cdot \mathrm{ma} \cdot \mathrm{ha}$ por los payas, waika por los de las islas de la bahía y zambos por los españoles.

El idioma miskito se habla en las tierras bajas de Nicaragua y Honduras, desde Laguna de Perlas en el sur hasta el río Negro en el noroeste y tan en el interior como la región de Bocay en el río Wangks o río Coco. Tres principales dialectos han sido encontrados allí: el tawira, de la laguna de Perlas a Bihmona, el wangki en el río Wanks o Coco, y el miskito hondureño, a menudo llamado ma $\mathrm{m}$.

mukula. Llamado el contra-frijol y la enredadera que lo soporta, Fevilea cordifolia (Sp. Chichimora), pero no es un frijol. La pulpa de la semilla, de color crema y muy amarga, cuando está fresca cura el reumatismo y las hemorroides. Es también ingrediente de un remedio de mordedura de serpiente bien conocido.

musukra. Lombriz suave de color claro que deja una secreción por dónde camina, que, si se toca, causa llagas en la piel.

na·klili. Nombre del legendario héroe que siguió el alma de su esposa a la tierra de los muertos y regresó.

na·kra kalkan uplika. Persona iluminada. Esta iluminación a veces se administra golpeando suavemente los ojos con una pequeña vara.

namakalmuk $\sim$ panamaka almuk. Acantilado en el Wanks, arriba de Kringkringya donde el río hace una curva muy aguda causando un remolino. Se dice que había sido el hogar de un demonio peligroso, 
quizás idéntico al li·wa, que consideraban así, hasta que un sukya lo alejó quemando un caimán en la playa de grava de Karsangkan.

\section{napinapi. Nombre utilizado para asustar a los} niños; se supone que es un demonio o un hombre caníbal.

no·aia du·sa. Especie de árbol, algo así como seda -algodón con madera muy suave; la corteza se utiliza como medicina para bañar a los niños y hacerlos crecer.

$\mathrm{o} \cdot$ hum (u.hum). ${ }^{25}$ Especie de palma, N.c: Elais melanococca, con ramas cortas, largas hojas y racimos de pequeños frutos rojos. En épocas de escasez, la carne de la fruta o la médula del tronco se golpean en el mortero y de él se hace una bebida que es nutritiva. De los granos se hacen dos tipos de aceite o de grasa: uno marrón, bueno para el pelo llamado en miskito batana (aceite), otro claro mal llamado kisu ma batana (aceite de la semilla del kisu). Ambos hacen un buen jabón con lejía.

o'kuli. Quien ha sido golpeado por un rayo y se ha recuperado y se ha convertido así en un pa'sa yapti (literalmente 'madre del viento') controlador de viento capaz también de ejercer una influencia mágica sobre plantaciones, asegurando buenos cultivos. Sólo puede haber un o'kuli a la vez. No es un chamán sukya sino un médium superior. Ver pa`sa yapti.

orus wanba (urus bamba) 26 dus alkaika puspusira. Una planta parásita aparentemente polypodium; su infusión, casi insípida, cura el bazo cuando hay malaria.

pakatpakat. Especie de pequeña ave palmípeda de color negro que se alimenta de peces, su nombre viene del golpeo de pies sobre el agua al comenzar su vuelo.

25 De acuerdo a Nelson Sutherland (2008), pg. 122, la planta llamada en miskito uhum o uhun (también batana) tiene como nombre científico Elaeis oleifera.

26 De acuerdo a Nelson Sutherland (2008), pg. 1079, la planta que en miskito es denominada 'urus bamba', en español denominada orégano de monte, juanilama y salvia santa, tiene como nombre científico: Lippia alba. palpa kwarka. Especie de árbol con frutas púrpuras pequeñas, utilizado para colorear tejidos de morado espléndidamente, pero el color se destiñe al lavado.

pa·nkalkal. Especie de árbol ${ }^{27}$, en inglés es llamado prickly yellow (amarillo espinoso). Se divide fácilmente cuando está recién cortado. Las decocciones de corteza administradas oralmente son reputadamente buenas para curar el sangrado persistente después de las mordeduras de serpiente.

pa $\cdot$ sa. Viento, brisa. En miskito no hay puntos de compás determinados por ningún punto fijo en el cielo excepto como se indica a continuación. De pie a la orilla frente al agua en frente (agua adentro) es lalma, a la izquierda es ya bra, a la derecha waupasa, detrás es muna.

En Nicaragua, donde la línea costera corre más o menos norte-sur, los nombres de direcciones y vientos son bastante constantes. Entre Cabo Gracias y Punta Patuca (Butukamaya, en la desembocadura del río Butuk o Patuca), todos los puntos cambian cuarenta y cinco grados más o menos. Desde la boca del Patuca hasta la aldea de Tocamacho - situada en el límite costero entre los departamentos hondureños de Gracias a Dios y Colón- unos cuarenta y cinco más. Mientras que continuando sobre la costa hacia el centro del departamento de Colón, en Iriona, pueblo costero que es cabecera de un municipio, ya'bra (que en Nicaragua sería norte) es en realidad sur oeste. Sin embargo, en Honduras, al parecer porque los miskitos de esas partes procedían originalmente de lo que es hoy Nicaragua y todavía pensaban en el sol que se levantaba en el lalma (mar adentro), las personas de Cabo Gracias y más allá se conocen todavía como lalma wina (gente del este). Tres puntos son invariables porque son fijados por el levantamiento de los cuerpos celestes:

El este: yu'mi'na (pies del sol) punto donde el sol se levanta.

27 De acuerdo a Nelson Sutherland (2008), pg. 988, este árbol que también es conocido en miskito como'sikiski dusa' (árbol de zorra) tiene como nombre científico: Zanthoxyoum ekmanii o Zanthoxyoum belicense. 
El noreste: u'hki' mi'na (pies de la osa mayor) punto donde se levanta la osa mayor.

El sureste; Li'watiskla li'watiskla mi'na (pies del escorpión) punto donde se levanta el Escorpión.

pa'sa yapti (literalmente: madre del viento). También se le llama o.kulli. A pesar del nombre este personaje es, por lo general, si no siempre, un hombre quien reclama el poder para controlar los huracanes. Es posible que pa.sa yapti sea realmente el nombre de un espíritu de alto rango que este médium dice representar. Compárese en la mitología mexicana a la esposa de Tlaloc, dios de la lluvia. No está claro si en estos días un pa.sa yapti se considera un súbdito de li.wa, la diosa del agua, o de alwoni, el dios del trueno. Puede haber solamente un pa.sa yapti (o.kuli) a la vez. Los tres últimos, al momento de escribirse este texto ${ }^{28}$ habían vivido en Kum, Sandy Bay y Auka, respectivamente.

pa $\mathrm{ya}^{29}$. Nombre de una tribu de indios antiguamente numerosos, poderosos, y que habitaban un amplio territorio. Ahora sólo se encuentran en o cerca de Dulce Nombre de Culmí, Carbón, el Río Paulaya y el río Ras. Exigieron tributo de los sumus en el río Butuk o Patuca hasta aproximadamente 1914. Se dice que un ejército de sumus cruzó sobre el Ras hace tiempo, para exterminar a los payas, pero dicho ejército fue completamente destruido. Probablemente no hay más de cuatrocientos Payas hoy en día, pero es posible que la tribu no se extinguiera, sino que fue absorbida por los matrimonios con los conquistadores ladinos. Monseñor Lunardi, legado papal a Honduras, ha publicado un valioso estudio sobre los payas.

pi ra kangbaia saika (litteralmente: remedio para expulsar la bilis). A veces un término usado en hechice-

28 Este artículo fue publicado en 1950, y el texto escrito anteriormente.

29 Los indígenas, anteriormente denominados payas y actualmente mejor conocidos como pech, continúan siendo repertoriados como uno de los grupos étnicos de Honduras. Aunque en peligro, la lengua sigue viva, y en los pueblos tradicionalmente considerados mayoritariamente pech vivían a comienzos del siglo XXI unas 3,000 personas según reportan diferentes estudios de esta época -ver texto y referencias citadas en: Griffin, Wendy; Martinez Escobar, Hernan y Hernandez Torres, Juana Carolina (2009). "Los pech de Honduras: una etnia que vive". Instituto Hondureño de Antropologia e Historia, Cuadernos de Antropología e Historia no.7. Tegucigalpa-. ría. Se cree que la malaria remitente biliosa se debe a la brujería. Dicen que como el diablo causa la enfermedad, su ayuda es necesaria para curarla por lo cual se requiere los servicios de un hechicero. El remedio utilizado es un baño de vapor hecho con hierbas mágicas.

pisik. La nuez del piñón y el arbusto que la soporta, Jatropha curcas (piñón). Las semillas son un laxante suave si se retiran los cotiledones, de lo contrario es peligroso. Las hojas también se aplican a hinchazones inflamatorias.

plas. Especie de banano corto y grueso (guineo cuadrado, chata, jam, guineo butuco, mojancho; en Tobago: banano, y en las Antillas orientales y San Vicente banano), con crestas muy marcadas en su cáscara y sabor no tan fino como el banano común. La fruta madura cortada en pequeños trozos y cocida sabe algo así como estofado de manzanas. La fruta no madura produce una buena harina. La planta puede permanecer en el agua tras una inundación durante dos semanas sin ser dañada.

prangs. Especie de banano, la más valorada, conocida en el comercio como Martinica, Jamaica o Gros Michel. Los indios afirman que había un banano nativo antes de la llegada de los hombres blancos, una variedad salvaje con carne blanquecina, leñosa e insípida, posiblemente el waki original de los Sumus. Un francés trajo la nueva y superior variedad al Wangki inferior. Después de su muerte prematura, los indios no sabían si la fruta era venenosa, pero persuadieron a una anciana, con la excusa que no podía vivir mucho tiempo en ningún caso, para probarla. Como lo había traído un «hombre de Francia», lo llamaron prangs.

prinsu. Nombre de una tribu de indígenas sumu. En guerras muy sangrientas casi fueron exterminadas. Se cree que los sobrevivientes, amalgamados con miskitos, constituyen los actuales habitantes de Tungla y Layasiksa, posiblemente también de Quamwatla.

puhlak $\sim$ puhulak $\sim$ purlak. El árbol de balsa ${ }^{30}$, N.cientifico: Ochroma bicolor, de madera suave muy ligera, fácilmente comido por las termitas. Es llama-

30 De acuerdo a Nelson Sutherland (2008), pg. 232, el nombre científico de este árbol, también llamado guano en español, es : Ochroma piramidale. 
do en inglés mountain mahoe, pero es bastante diferente del mountain mahoe de Jamaica cuya madera es dura y azulada. Puhlak también significa las fibras del fruto de la balsa, similar al kapok de Java.

pukru. N.científico: Pachira aquatica. Llamado en inglés 'provision tree'. ${ }^{31}$ Las semillas y las hojas, hervidas, según algunos son comestibles. Las ramas más grandes del tronco hacen buenos postes vivos para cerca. Los criollos utilizan una infusión de la corteza en vez del té.

punta.ra (abreviación de 'punu tara'). Guanábana. Nombrecientifico: Anona muricata. Llamada en inglés: soursop. La infusión de un puñado de sus hojas en medio litro de agua, mata piojos y pulgas. Una copa de una infusión fuerte pone sobrio a un hombre borracho en quince minutos; y una infusión de solo tres hojas antes de una comida alivia la dispepsia y, según se dice en las Antillas, facilita el sueño. Una pomada hecha con semillas maduras trituradas mata piojos. Las semillas o las hojas probablemente serían antiparasitarios contra los helmintos o lombrices.

pu · nu. Una especie silvestre de anona, Anona palustris, que crece en tierra pantanosa, con una fruta algo parecida a una chirimoya, pero no comestible porque consiste casi en su totalidad de semillas con muy poca pulpa. La madera es suave y ligera y se utiliza para los carretes de arpones.

pyu • ta kaiora $\sim$ pyu $\cdot$ ta du·sa. ${ }^{32}$ En inglés $\mathrm{cra}$ manty tree o coby wood. Al parecer una especie de abedul. La corteza, que es amarga, se quita fácilmente; en el interior es de color rosado y tiene olor a cuero ruso. La decocción: una onza por medio litro, administrada en dosis de una cucharada cada media hora, cura la mordedura de serpiente. Aplicada con un paño en las heridas infectadas saca el pus. Su poder es aumentado agregando una onza de Sal Epson por medio

31 Nelson Sutherland (2008), pg. 232, confirmando el nombre científico atribuido por Heath aquí, reporta que en español el árbol es llamado, entre otros nombres: zapote de mico, zapotón, poponjoche y lirio de montaña.

32 Nelson Sutherland (2008), pg. 995, identifica un pyuta dusa (el término es usado para varias plantas) o pyuta karka miskito con el nombre científico: Matayba opposifoliata. Esta planta es llamada vulgarmente en español: cola de pava, fierrillo, zorrillo y palo culebra, entre otros nombres. litro. Para la malaria, las hojas pequeñas son mejores. Para los adultos, la dosis es de doce hojas. La madera, rosada y amarga, no es atacada por las termitas y es excelente para el trabajo de ebanistería y para sacar pequeños cuartones. Se dice que es medicinal.

pyu.ta saika. Medicamentos para curar la mordedura de serpiente. Existen muchos, pero no de igual eficacia. Su mayor eficacia se atribuye a una yerba no identificada, con una raíz pimentosa, conocida por los ulwa y otros sumus y llamada sirsaika ${ }^{33}$. Es muy común en las antiguas plantaciones y en las orillas de los ríos. La víctima de la mordedura de serpiente, después de atar la extremidad por encima de la mordedura, debe poner las hojas machacadas en la herida inmediatamente, cambiándolas más o menos cada hora, y al mismo tiempo masticar un poco de las hojas cada pocos minutos tragándose el jugo. Esto debe continuar hasta que otros remedios estén disponibles, pero muchos consideran que la sirsaika es suficiente en sí misma. Algunas personas prefieren usar la raíz. Poner las hojas machacadas de cualquiera de las Aristolochias en la mordedura y hervir alrededor de tres pulgadas de la vid espesa, cortada en pedazos pequeños, en dos copas de agua. Dosis: media copa cada media hora. En los peores casos tomar tres pulgadas de cada uno Aristolochia guaco y Aristolochia trilobata $^{34}$. Los remedios de serpiente también han demostrado ser eficaces contra la viruela, la malaria y la disentería. Hervir tres hojas de cualquiera de las Aristolochias en un poco de agua para cada dosis y repetir cada dos o cuatro horas. Para la viruela o la enteritis hervir un puñado de hojas sirsaika en una pinta de agua y dar una cucharada cada dos a cuatro horas, en casos graves cada media hora.

rah. Una raza de indios altos y feroces, según la tradición hondureña, reputados caníbales, que vivían en Raiti tara y sus alrededores, por debajo de la aldea de Krupunta, en el río Butuk (Patuca). Condujeron expediciones de guerra hasta Trujillo. Finalmente

33 En el diccionario de Heath y Marx (1961), esta planta (sirsaika - sirh saika) es denominada escoba amarga en español, pero ver aquí mismo adelante la entrada para la planta sirsaika.

34 Varias de las Aristolochia son conocidas vulgarmente como guaco; y la Aristolochia trilobata como crucita o media luna, ver Nelson Sutherland (2008), pgs. 131-133 
fueron absorbidos por los miskitos que vinieron más tarde. Sus descendientes siguen siendo señalados en el Butuk y en Brus y Kokobila.

ra.ma. Nombre de una tribu de indios ahora casi extintos $^{35}$, pero de los cuales los pequeños remanentes se encuentran en ciertos puntos desde Rama Cay, en la laguna de Bluefields, hasta la cabecera del río Frio en Costa Rica. Aquellos que están en Rama Cay fueron traídos allí por los miskitos y mantenidos por ellos en servidumbre. Su lenguaje es totalmente distinto, en estructura y vocabulario, del grupo miskito-sumu. Ellos llaman a los miskitos: pakba.

rami du·sa. Especie de helecho arbóreo, también llamado li·mi du·sa, árbol del jaguar, porque su hoja no abierta se asemeja al pie de este felino.

ramung ${ }^{36}$. Especie de árbol alto con madera dura. Las incisiones en la corteza exudan cantidades muy pequeñas de leche sabrosa. (Wangki).

riruk (rihrut). Especie alargada de la planta parecida al plátano, con flores escarlata, en inglés llamada wild plantain; y en español, platanilla; aunque no es un plátano en absoluto. La raíz de una variedad enana es un remedio eficaz para mordedura de serpiente, no amarga (J.E. Lewis) ${ }^{37}$.

sahkal. ${ }^{38}$ Dos especies -una roja (pauni) y otra blanco (pihni)-de un árbol; ambas son llamadas en español querosén. Es similar al santa maría y bue-

35 El idioma rama está muy en peligro de extinción, con solo algunas decenas de hablantes o semi-hablantes, pero el grupo étnico tiene unos 1.000 miembros entre Rama Cay, donde está el principal asentamiento, y otras aldeas en tierra firme: ver diferentes escritos de Colette Grinevald en nuestra revista Wani (nos. 12, 6 y 4, entre otros).

36 De acuerdo a Nelson Sutherland (2008) pgs. 736-737, el árbol de nombre científico Brosimum alicastrum, es llamado ramón en español, de donde el término ramung pareciera provenir. Esta planta, según la misma fuente, y en miskito es llamado unta kurka (níspero de montaña) y pisba wainhka (ojoche macho). En español, además de ramón y ramón colorado, es también llamado palo de leche y ojoche blanco, entre otros

37 El nombre científico de esta planta es Heliconia pogonantha: Nelson Sutherland (2008), pg. 621

38 Nelson Sutherland (2008), pg. 268, da el nombre científico Protium glabrum para el árbol que en miskito es llamado sahkal pihni (también usra dusa: arbol comején), en español además de querosén es llamado cola de pava. El Tetragastris panamensis, es también llamado sahkal en miskito y querosén o curtidor en español. no para madera de canoa y para leña. Produce fruta comestible. El sahkal pauni (rojo) arde como madera de pino y enciende incluso cuando está húmedo.

sakaldakawa. La olla de cocinar del pájaro sikla. En la leyenda de Na.kili, el alma llega a un abismo unido de lado a lado por un solo pelo que se tiene que cruzar. Debajo está una olla hirviendo atendida por un pájaro sikla. Si la persona durante la vida terrenal ha sido tacaña con el alimento, el alma cae en la olla y perece.

sa·lai. Nombre de una montaña alta en la cabecera del arroyo Wani, es la más alta de Nicaragua, 6500 pies, considerada por los sumus como la morada de los espíritus malignos.

sa·mu. ${ }^{39}$ Especie de árbol (en español: leche amarilla) cuya corteza contiene una resina amarilla. La madera del corazón de los árboles grandes que crecen tierra adentro es muy pesada, de color amarillo brillante y duradero, pero la madera blanquecina de los árboles jóvenes que crecen en la arena es rápidamente devorada por las termitas.

sa·ni. En inglés mahoe, en español majagua, majana o majao $^{40}$. Su corteza tiene muchos usos como sustituto de la cuerda o para hacer una especie de correa y también cordeles para hacer bolsas de red. La madera de las ramas jóvenes es, en la mayoría de las variedades, ligeras y suaves y se utiliza para corchos, pero el corazón de madera de los árboles viejos es duro y muy durable.

sauru $^{41}$. Especie de planta trepadora robusta, bejuco medicinal, con flores moradas, que crece sólo en la playa del mar por encima de la máxima marca de agua (marea alta). Una decocción de las hojas se utiliza para lavar los pies y otras partes afectadas con comezón de pantano. Los criollos la llaman bayvine (que

$39 \quad$ Nelson Sutherland (2008), pg. 302, identifica con el nombre científico Symphonia globulifera, al árbol llamado samu o musukra en miskito, y que en español recibe los nombres de leche amarilla, leche de Maria, varillo o cerillo, entre otros.

40 De acuerdo a Nelson Sutherland (2008), pg. 700, el nombre científico de esta planta es: Talispariti taliaceum.

$41 \quad$ Nelson Sutherland (2008), pg 321, identifica la planta llamada sauru o sa.haru en miskito con el nombre científico: Ipomea pes-caprae. En español es llamada bejuco de carey o bejuco de cintura. 
significa vid de playa), tanto al sauru como al kaisni pata (comida de cangrejo), un bejuco con flores amarillas; pero las plantas son muy diferentes.

si ka dingkaia. Dar un baño de vapor con la de ebullición de ciertos remedios vegetales. O, a veces, con el humo de la quema del nido de termitas. Aparte de inducir la transpiración copiosa, estos baños son valorados debido a los supuestos efectos mágicos de algunas de las hierbas utilizadas -llamadas kangbaika- para contrarrestar los efectos de "venenos" que proceden de brujería. Algunas enfermedades, como la fiebre remitente biliosa y algunas formas de reumatismos, se piensa que se deben a causas sobrenaturales y por lo tanto no curables, excepto por la ayuda de los demonios trabajando a través de las hierbas. Algunos piensan que el efecto sólo puede obtenerse si se paga a las plantas de las que se toman las hojas: sea vertiendo caldo de cerdo sobre una planta de este tipo o poniendo una moneda en la raíz y dejándola allí por cierto tiempo. A veces se realiza una danza mágica. Muchos cristianos ahora afirman usar este tratamiento de si $\cdot \mathrm{ka}$ dinkaia divorciado de las prácticas y creencias supersticiosas.

si kakaira ${ }^{42}$ (en Honduras: kalila saika). Albahaca silvestre, utilizada con carnes y en sopa; se dice que combate los parásitos intestinales aun inyectado por los oídos o nariz. Sirve también como carminativo: para expulsar los gases del tubo digestivo.

$\mathrm{si} \cdot \mathrm{kra}^{43}$. Guayaba. Una decocción de la corteza es útil en diarrea y disentería. Una infusión hecha pulverizando la corteza en agua fría ha sido usada exitosamente para retirar una película blanca de la córnea al empaparla en ella.

siksa labuka. Base de la cepa del banano utilizada como un medicamento para la disentería y diarrea violenta. Rayar, lavar con agua y dar el almidón como atol, pero en pequeñas dosis ya que causa estreñimiento. Sin embargo se utiliza como alimento en tiempos de hambruna.

42 De acuerdo a Nelson Sutherland (2008), pg. 640, la planta llamada kalila saika en miskito, albahaca de monte en español, tiene como nombre científico: Ocimum campechianum.

43 De acuerdo a Nelson Sutherland (2008), pg. 772, el nombre científico de la planta llamada sikra en miskito es: Psidium guajava. siksakumaik (literalmente: dameunbanano). Especie de pájaro similar al a'yalila (en español: zorzal cenzontle); grita: sol-sol-do-si-re.

si·na: senna (Nombre científico: Senna occidentalis) Una variedad nativa del senna, casi idéntica a la de Egipto e India, que se encuentra en las orillas del Wangki y del Butuk (Patuca), pero parece no tener ningún nombre nativo. Las hojas del sinsinya son también un sustituto práctico del senna (para los usos ver párrafo siguiente), así también las hojas del cassia siamea (término científico que designa una variedad de senna), un árbol utilizado con fines ornamentales en la Mosquitia.

sinsinya $\sim$ slinslinya. Una hierba común, Cassia laevigata, término que designa una variedad de senna (en el río Wangki es llamada go ts pata -literalmente 'comida de cabra'; Sp. frijolillo). Tiene flores amarillas. Las semillas tostadas se utilizan como sustituto del café; las hojas son un buen sustituto de senna en dosis como de cuarenta hojitas. En pequeñas dosis, tres hojas de árbol para un adulto, una hoja para un bebé, a menudo repetido, la infusión caliente aliviará la retención de orina donde no hay estenosis, de ahí el nombre vulgar en inglés criollo pissabed (orina en cama). Se dice que las raíces amargas, tras decocción, alivian el dolor abdominal.

sirsaika $\sim$ dus saika $\sim$ kya.ya saika $\sim$ ma.tis pata $\sim$ yu.kri saika. Llamada en inglés bitter brom weed. En español llamada equivocadamente: culantrillo (inglés: maidenhair) o mastuerzo (inglés: water-crees). N.científico: Scoparia dulcis. ${ }^{44}$ Considerada como un remedio para la picazón. También un remedio valioso, no venenoso, interno y externo, para la mordedura de la serpiente, otras mordeduras y picaduras, forúnculos, viruela, enteritis, tos, dolores en el útero y reumatismo.

si·sakna. Una erupción comúnmente en la cara, dolorosa, con picazón y acuosidades como am-

44 Nelson Sutherland (2008), pg. 1017, señala, para la importante planta medicinal Scorparia dulcis los nombres brus tahpla (literalmente escoba amarga) y chicken weed en miskito e inglés respectivamente. En español, además de culantrillo y mastuerzo señala las denominaciones alternativas: arrocillo, contrayerba, culantro de pollo, escobilla, escobilla blanca, mostaza, pulguilla y verbena silvestre. 
pollas. La causa es desconocida, la curación se dice que es una decocción de una especie de planta espinosa con ramas y raíces rojas.

sisip. Especie de planta, algo como hibisco ${ }^{45}$, con hojas pegajosas y flores rojas. Con las hojas maceradas en agua se puede hacer un medicamento para la higiene y protección de la piel que se dice es también un expectorante.

snik. Llamado en inglés: pigeon pea, congo pea o goongooo. Nombre científico: Cajanus indicus; según Heath y Marx (61): una especie de arveja o garbanzo. Es un alimento valioso. Las hojas son usadas como remedio para la tos, también como substituto para el jabón, y para aumentar grandemente la fuerza de bebidas fermentadas.

spi·kin. Del inglés 'speaking' (en español: entrevista). En las estaciones de los misioneros moravos, las entrevistas periódicas personales con el ministro/reverendo para el consejo espiritual y la instrucción, especialmente en la preparación para la Santa Comunión, Bautismo, Confirmación o Matrimonio. Un hombre y su esposa pueden asistir juntos, sino, por lo general. cada quien individualmente. No se trata de una confesión auricular.

spirit uplika. Una especie de hechicero que utiliza la nomenclatura cristiana y pretende ser inspirado por un buen espíritu de Dios o incluso por el mismo Espíritu Santo.

sru $\cdot$ hi. ${ }^{46}$ Especie de árbol de sombra, de hojas pinnadas (opuestas como espinas en la rama) muy difícil de matar. La fruta es reputada de ser venenosa. Se dice que la corteza es un antiparasitario general eficaz, pero también un purgante vomitivo peligrosamente violento.

45 La planta llamada sisip en miskito es identificada por Nelson Sutherland (2008), pg. 693, con el nombre científico: Malviscus arboreus. Según esa fuente, también recibe en miskito el nombre de sukún-lala (literalmente sukun amarillo, aceituno amarillo) y tininiska pata (literalmente: comida de colibrí). En inglés es llamada wild mahao (mahao silvestre) y en español: avispón, botoncillo, chupachupa, chupamiel, huesito, mapola y siempre verde. Heath y Marx (61) dan como equivalente español del sisip o tininiska pata, el término tatascán .

$46 \quad$ La planta llamada sru.hi en miskito, es identificada por Nelson Sutherland (2008), pg. 639, con el nombre científico Leonotis nepetifolia, y en español es llamada molinillo. suklin dwarka (literalmente canoa de sapo). Una pequeña canoa tripulada por sapos que se supone transporta almas incorpóreas al otro lado del río al final del viaje a Yapti misri. Por lo tanto cualquier canoa muy pequeña, especialmente una canoa de juguete.

sukun $^{47}$. Especie de árbol (español local: aceituno; inglés criollo: School Tree) con tronco recto y hojas pinnadas. El fruto es una drupa; de las semillas se obtiene un aceite de cocina verdoso, apetecible. Se dice que la corteza es muy eficaz contra la malaria o la disentería. La dosis para adultos es así: una decocción de aproximadamente cuatro pulgadas muy finamente cortadas, cada dos horas. La madera es amarillenta, de peso ligero, muy fácil de aserrar, resistente a las termitas pero, como la caoba, no se utiliza para los postes plantados en el suelo.

sukya $\sim$ su.kya $\sim$ sukia. Hechicero, brujo, chamán; alguien que afirma ser el medio de un espíritu o de espíritus, cada uno de ellos representado por bastones especialmente preparados, y por cuyos poderes puede curar enfermedades.

Sum. Olmo en español estándar, Cordia Gerascanthus (en Honduras llamado ma'ni· du'sa”; en inglés criollo samwood y en español local laurel) un árbol valioso. La madera del corazón es de color marrón oscuro, y es prácticamente indestructible, incluso plantado en la tierra; pero la madera de cualquier parte donde circula la sabia es inútil. La madera tiene la fuerza de la caoba y la fragancia del cedro. De los árboles muy grandes se puede hacer canoas.

Sumbulo. Término aplicado a un número de personas en la región y comunidades hondureñas de Laka, Tipi y Auka, departamento de Gracias a Dios, y algunos otros que se caracterizan por un crecimiento desproporcionado de los miembros (acromegalia). Se dice de ellos que todos son descendientes de una niña que fue robada por marineros miskitos de un pueblo indígena de otra tribu más allá de Omoa.

47

El árbol llamado aceituno en español y sukum en miskito es identificado con el nombre científico Simarouba amara por Nelson Sutherland (2008) pg. 1019. Ahí se señala que también es llamado en español: jeto, jeto macho, marapa, naraco y negrito. En miskito es también llamado lal tanhta (cabeza chata) y en inglés bittercup y soapseed. 
$\mathrm{su} \cdot \mathrm{mu}^{48}$, Una raza de indígenas muy cercana a los miskitos que una vez ocupaban una amplia zona: desde El Salvador hasta el sureste de Nicaragua. En la actualidad, el grupo má más grande al norte, generalmente llamado simplemente sumu, comprende las tribus Twahka y Panamaka con las cuales en el Bambana y el Wawa se han amalgamado los sobrevivientes de los $\mathrm{Ba} \cdot$ wihka. Los Twahka se consideran la nobleza. Su dialecto difiere apenas levemente del Panamaka. Las tribus que prácticamente han desaparecido son Prinsu, Si • lam, Ku, Yusku, Bo • a y Kukra. Estos últimos tres forman parte del grupo meridional, representado ahora sólo por los Ulwa $\sim$ O·hlwa $\sim$ Wulwa, cuya lengua difiere del Sumu del norte casi tanto como el holandés del alemán. La Zentralamerika del Dr. Walther Lehmann menciona el remanente de otra tribu, la cacaopera en El Salvador. Excepto en Karawala, los Sumus viven en el bosque a orillas de los ríos. Ellos a menudo pronuncian su nombre sumu o casi sumú.

sya $\cdot$ kwani saika. ${ }^{49}$ Ciertas hojas, quizás el cornejo (dogwood en inglés) nativo; la decocción se utiliza para bañar bebés que tienen una especie de diarrea que se supone causada por ver al sya $k$ kwani, una serpiente delgada de un verde brillante (llamada culebra sabanera en Heath y Marx (61)), bastante inofensiva.

$48 \quad$ Actualmente los sumus del norte -panamahkas y twahkas de Nicaragua y tawahkas de Honduras- son también conocidos como mayangnas; el término "sumu", de origen miskito, siendo considerado peyorativo. Los ulwas viven principalmente en la comunidad de Karawala, en la Región Autónoma de la Costa Caribe Sur en Nicaragua.

Basándose principalmente en las investigaciones del lingüista costarricense Adolfo Constenla, es generalmente aceptado que la familia de idiomas misumalenca incluía además del miskito y el sumo que están todavía vivos, a los desaparecidos matagalpa-cacaopera y lenca (y por consiguiente a las variantes o dialectos de cada uno de ellos). La subfamilia misumalpa -que no incluye al lenca pero si a los otros tres- forma un grupo más homogéneo y mejor conocido, el matagalpa y el sumo son más cercanos entre sí. Pero la distancia entre cada uno de los miembros de la familia misumalenca es bastante grande. Según las apreciaciones de Constenla tendrían todos más de 5,000 años de separación entre si: Constenla, Adolfo (2002). Acerca de la relación genealógica entre las lenguas lenca y las lenguas misumalpa ver Revista de Filología y Lingüística XXVIII (1) 189-205. Universidad de Costa Rica.

49 Nelson Sutherland (2008), pg. 1092, identifica la planta utilizada para preparar el sia.kwani saika con el nombre científico: Cissus microcarpa. Común en las montañas del departamento de Chontales en Nicaragua donde recibe el nombre de comemano en el español local. ta la pra'kaia (literalmente 'cerrar sangre'). Una ceremonia en la cual el sukya o el chamán pasa un hilo de algodón a través de un agujero en su lengua de modo que el hilo se empapa con sangre y después ata el hilo empapado con muchos nudos alrededor del cuerpo de su paciente para prevenir el retorno del espíritu de la enfermedad que ha sido expulsado.

tata $\cdot \mathrm{ku} .{ }^{50}$ Especie de enredadera. ¿Una especie de ipomea? Llamada en inglés miskito: withe (mimbre o junco), usada como purgante y para coagular caucho. En el Wangki y en Honduras, varias otras enredaderas son llamadas así, especialmente unas con racimos de grandes flores carmesí.

ti. En inglés lemmon grass y fever grass (Nombre científico: Andropogon citratus o Cymbopogon citratus), en español: zacate (de) limón o de té, y la infusión o té hecha de ellos. Comúnmente tomado con las comidas y a menudo se llama ti aingwa (té verdadero) en contraste con el té comercial que se llama inglis $t i$ (té inglés). En dosis frecuentes es un sudorífico fuerte y diurético y por lo tanto se da en las fiebres. Precedido por una purga ha demostrado ser un remedio especial para la gripe y su uso diario durante una epidemia de influenza es profiláctico. Definitivamente no cura la malaria.

to $\mathrm{krun}^{51}$ Especie de árbol grande (en español gualiqueme) cubierto de espinas, que crecen en tierras pantanosas, teniendo en febrero grandes racimos de flores dulces, comestibles, color salmón. Las hojas, no más de tres para una dosis, se dice que son anodinas hipnóticas. Las ramas plantadas para el poste de la cerca crecen fácilmente. La Botica del Pueblo de Francisco Cruz, $3^{\mathrm{a}}$ edición revisada por Julián Cruz, afirma que la decocción de la corteza es sedante y ligeramente narcótica sin efectos negativos; Tam-

$50 \quad$ Nelson Sutherland (2008), pgs. 316 y 471 respectivamente, identifica dos plantas que en miskito son llamadas ambas tatah·ku : una especie de bejuco cuyo nombre científico es Ipomea aquatica, y una planta cuyo nombre científico es, Centrosema pubescens, llamada en español indistintamente: frijolillo, gallinita, gallito y sonajera azul.

$51 \quad$ Nelson Sutherland (2008), pg. 488, identifica a esta planta, llamada gualiqueme, guiliqueme o guilequeme en español, en miskito tukurun o tuburun y en mayangna-twahka tu-krun, con el nombre científico: Erythrina fusca. 
bién alivia la supresión de la orina. En El Salvador se afirma que cura la disentería, hemorragias, furúnculos, hidropesía, catarro y dolores de cabeza.

Tuburus. Especie de árbol grande, nombre científico Enterolobium cyclocarpium, en español: guanacaste, con hojas pinnadas y madera duradera de grano cruzado buena para canoas, cuartones y tablas. Según Cruz (ver referencia en la entrada anterior), una decocción de la corteza administrada internamente junto con la aplicación frecuente de un yeso de la fruta triturada curará la mordedura de serpiente.

tuktukya $^{52}$ (1). Especie de palma cuyas hojas se utilizan para azotar los pies de los niños para hacerlos caminar más pronto. (2) Una hierba con pequeña semilla redonda en la base de la flor verde con forma de vejiga, usada como medicina contra serpiente, interna y externamente.

tunsirpi ${ }^{53}$. En inglés criollo: miskitu banyan (higo miskito). Una decocción de la corteza aplicada a las heridas laceradas es marcadamente antinflamatoria y astringente. Pero debe aplicarse con cautela o la piel se formará antes de que los tejidos subyacentes estén libres de pus. Al mismo tiempo pirofosfato de hierro debe administrarse por lo menos una cucharadita cada hora, hecha de la solución de un grano en doce onzas líquidas de agua pura.

tu·nu. Una de las plantas conocidas por el nombre genérico de origen malayo: gutapercha, Castilla fallax ${ }^{54}$ o especies similares. También, la resina obtenida de él, la tela de la corteza o manta obtenida tras pelar largas longitudes de corteza del árbol $\mathrm{y}$ golpeadas en un banco bajo con un disco duro y entallado. En este proceso, la corteza se extiende a

$52 \quad$ Nelson Sutherland (2008) proporciona nombres científicos para dos plantas llamadas tuktukya en miskito. La primera (pg.973), también llamada dus wapni (palo recto) en miskito, es la Psychotria simiarum. No proporciona nombre vulgar en español. La otra planta Physalis ignota, que además de tuktukya es también llamada rumbu en miskito, recibe en español los nombres: farolito, bomba, tomatillo y vejiga de perro.

53 Dado el nombre en inglés criollo esta entrada probablemente se refiere a kru sirpi, en español higuillo y nombre científico Ficus americana.

$54 \quad$ Nelson Sutherland (2008), pgs. 737 y 738 proporciona para dos plantas llamadas tunu en miskito los nombres científicos Castilla elástica y Castilla tunu. la anchura requerida. En épocas anteriores y todavía recientemente, para algunos sumus este paño se utilizó como la única ropa, haciendo tapa rabos masculinos y tiras de delantales femeninas. La forma twa'nka, doble construido de tunu:-> 1.tw-a-nu ->2 twan-ka, y sus derivados (twainka o twainki ...etc), eran también, por metonimia eufemística, utilizadas de las partes íntimas femeninas. Estas eran firmemente cubiertas por una tira de tela de corteza colocada en cada extremo en una madeja de algodón enrollado alrededor de la cintura de modo que el tu 'nu cuelga abajo, en frente y detrás, de ahí el nombre de la vagina, apropiadamente, ratka. En los últimos años (1945) los indios del Alto Wangki han restringido estas inflexiones, y se ofenden si se utilizan para el paño de corteza para las que parecen utilizar un nuevo conjunto de inflexiones, tu ' nu $\cdot \mathrm{ka}$ (tunuki, tunukam.. etc). Esta distinción todavía no se hacía en 1920, ni tampoco los indígenas hondureños la aceptan.

twas papaw. Nombre científico: Carica papa$y a$, (en español papaya). Las semillas de la papaya madura, bien secas y bien trituradas, forman un excelente sustituto de la pimienta negra. Son un antiparasitario excelente, fresco o seco pero triturado, dado por la noche y seguido de una purga por la mañana. La dosis para niños es una cucharadita y para adultos una cucharada, mezclada con azúcar, jarabe o miel. Los mejores resultados son tres dosis, noche, mañana, noche, con purga final en la mañana siguiente. La leche y las hojas también son antiparasitarias. La carne envuelta en las hojas y cocinada o frotada con la fruta madura antes de cocinarse se pone suave pero debe ser comida el mismo día. Un jarabe hecho con el jugo de la fruta madura horneada es un remedio excelente para todas las toses, incluso para la tuberculosis.

twî wihta lâ daukisa. El magistrado de la sabana está haciendo la ley, dicho eufemístico de ir al excusado (Ziock).

udo (udu). Dios Luna de los sumus. Compañero de uhubapút pero inferior a él. El planeta Venus cuando se ve por encima de la luna creciente es considerado como su esposa.

Uhubaput. Dios Sol de los sumus, su suprema deidad; se dice que ha hecho el mundo y ha nombrado 
a alwoni (alwani) como su virrey, instruyéndole en cómo gobernar.

$\mathrm{u} \cdot$ lak $\sim \mathrm{u} \cdot \mathrm{luk}$. Mono antropoide, gorila. Evidentemente una tradición africana, pero los indios insisten en que, aunque nadie vivo hoy en día lo ha visto, solía encontrarse en varias localidades y hay una leyenda sobre un $\mathrm{u}$ · lak que tenía una mujer miskita como esposa y tuvo hijos por ella. Los adultos y los niños reconocen inmediatamente una imagen de un gorila como un u · lak. Se decía que hacía un llamado: $\mathrm{u} \cdot \mathrm{u} \cdot \mathrm{u} \cdot \mathrm{ulak}-\mathrm{lak} \cdot \mathrm{lak}$.

unta da 'wan $\sim$ unta du.kya. Señor del bosque, el más temido de los espíritus mayores. Los sukyas dicen que se les aparece a ellos en forma de jaguar. Otros le atribuyen la forma de la serpiente dueña del monte. Otros reconocen al unta du kya como hombre pero de varios colores.

usnung ustun. ${ }^{55}$ Especie de planta parasitaria con hojas grandes similares a las del árbol fruta de pan. Es una trepadora de tronco muy robusto, y largas y fuertes raíces aéreas utilizadas para atar las maderas de una casa y para hacer fuertes bolsas de malla gruesa. La bolsa también se llama usnun o ustun en Honduras.

waha $^{56}$. Hoja. Especialmente una especie de hoja muy grande, la hoja de Calathea insignis, (1lamada bijagua en español según Heath y Marx (61)) la cual a menudo alcanza el tamaño de tres pies por dos. Utilizada por los miskitos como plato para comer, también para construir parcelas impermeables o para el revestimiento de cestas pataki (un tipo de canasta impermeable indígena). La palabra significa a menudo paja en general.

$55 \quad$ Nelson Sutherland (2008), pg. 106, proporciona el nombre científico Syngonium podophyllum para una planta que en miskito es llamada ustun (pauni) y también plun damni (comida dulce). En español recibe los nombres de: amor de hombre, guineíto, mano de león y pica pica. En inglés wild banana.

56 El termino waha como sugiere Heath, es probablemente un término genérico para referirse a hojas grandes, Nelson Sutherland (2008), pgs. 619-621, proporciona los nombres científicos de dos plantas identificadas en miskito como waha: Heliconia Hirsuta y Heliconia pagonangha. Para ninguna de las dos proporciona nombre vulgares en español, pero para la segunda proporciona alternativamente el nombre miskito rihrut y el tawahka wakipan. waisaku. Pájaro del banano (Ziock), un pájaro del tamaño de un canario grande, de un amarillo rico con marcas negras; pero otro tipo es algo gris. Dice una variedad de cosas en miskito, por ejemplo: "un pájaro bonito", "dáselo a Pedro "," comámoslo", cada uno repetido varias veces.

waiwan $\sim$ waiwin. Especie de espíritu maligno que puede supuestamente causar enfermedades. Hay quienes dicen que es el caballo del sukya, con ojos vidriosos que brillan en la noche. Vive bajo la tierra, de donde no suele salir y sólo espía. Si sale, la gente muere.

wakumbai. Un demonio o fantasma que se dice tiene la forma de una vaca, según otros un caballo, pero de una sola pata. Según Conzemius, tiene una sola pierna delante y dos detrás y es el propio karswaki (ver arriba). Aparece si alguien mata al pájaro llamado kataukatau ${ }^{57}$ o pnamaka yu·la.

wasaki. Tipo de convulsión en recién nacidos. Se dice de ellos que 'wasaki daukisa' (literalmente 'hacen wasaki' o 'el wasaki les hace'; compárese kauhla daukisa: literalmente frio hace: hace frio). ¿Son afectados por wasaki? Se dice que estos estremecimientos y ataques son causados por la visión de una mujer embarazada. Pero el maleficio se rompe dándole al infante un trozo de tela o cabello de la mujer embarazada y atándoselos a la mano o al pie del niño. Según Conzemius, sin embargo wasaki es una marca de nacimiento que se parece $u$ origina en la necesidad que habría afectado a la madre por una fruta o alimento que había anhelado intensamente durante el embarazo pero no había podido obtener.

waual, Una criatura similar a un dragón que supuestamente se introduce a un río desde el mar y vive cerca de las cabeceras. Cuando baja de nuevo hacia el mar sus alas barren el agua frente a él causando un diluvio.

57 Según Heath y Marx, el kataukatau es el cuervo (come avispas) también llamado en miskito panamahka yula (literalmente compañero o mascota de los panamahka- uno de los grupos mayangnas o sumus del norte). 
Waula. Boa constrictor. Los caribes afirman que su mordedura, generalmente inofensiva, es venenosa en julio porque la saliva se mezcla con el jugo de bayas que sí es venenosa cuando entra en el torrente sanguíneo. Waula tara es una fabulosa boa gigante que se dice vive en la cabecera de ciertos arroyos y se traga los botes o canoas.

wislu •. Especie de árbol muy duro de matar. En Dakura es identificado con el dogwood nativo, en inglés llamado Jamaica dogwood. Nombre científico: Piscipia piscipula. De este árbol se dice que las hojas son veneno para los pescados y las raíces narcóticas.

won aisa $\sim$ wonaisa $\sim$ wol aisa. El Padre, Dios. Los viejos indios de la generación pasada afirman que el concepto no es originalmente indígena, sino que se adaptó, desde hace mucho tiempo, de los blancos, presumiblemente españoles. Pero actualmente es ciertamente propio de los indígenas. Estrictamente, el significado es algo impersonal, casi el Padre universal. "Padre Nuestro " es 'Ya'won Aisa'.

Yahal. Especie de arbusto o árbol. Nombre científico Curatella Americana, cuyas hojas son muy ásperas y se pueden utilizar como sustituto de lija.

Yaptimisri. La diosa del reino de los muertos, yaptimisri kuntri. Se considera que es la madre de todos los miskitos y se describe con innumerables pechos.

yukwaika yukaihkai. ${ }^{58}$ Maleza florida amarilla marrón, con raíces muy duras. Una infusión fría hecha macerando las hojas en agua fría es un remedio inofensivo administrado oralmente para la fiebre, el vértigo, y el dolor de cabeza.

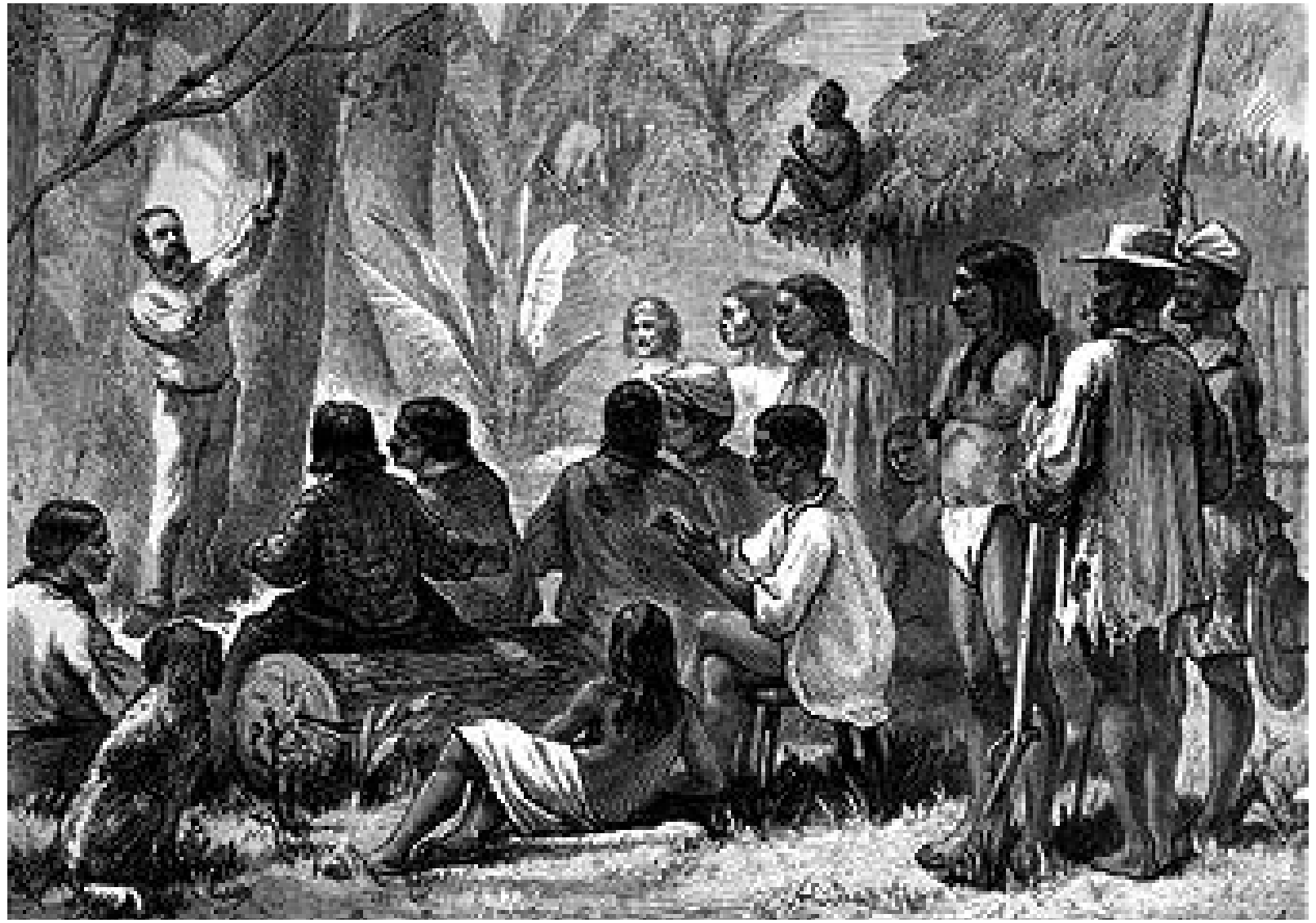

Dibujo que muestra a misionero moravo predicando a indígenas (archivo Wani)

58 De acuerdo a Nelson Sutherland (2008), pg. 696, la planta llamada en miskito yukaihka o también yu tawa, tiene como nombre científico Sida acuta, y en español recibe los nombre de: escoba babosa, escoba lisa, escobilla, malva de chancho y malva murruca. En inglés es llamada broom weed y baby aniseed. 